\title{
Seed dispersal in heterogeneous landscapes: linking field observations with spatially explicit models
}

\author{
Jessica E. Lavabre ${ }^{1 *}$ Daniel B. Stouffer ${ }^{2}$, \\ Rúben Sanz ${ }^{3}$, and Jordi Bascompte ${ }^{1}$ \\ ${ }^{1}$ Integrative Ecology Group \\ Estación Biológica de Doñana, CSIC \\ C/ Américo Vespucio s/n, 41092 Sevilla, Spain \\ ${ }^{2}$ School of Biological Sciences \\ University of Canterbury \\ Private Bag 4800 \\ Christchurch 8140, New Zealand \\ ${ }^{3}$ Forest Research Group \\ School of Forestry, University of Extremadura \\ Av. Virgen del Puerto 2, Plasencia ES-10600, Spain \\ February 17, 2014
}

${ }^{*}$ Corresponding author: jessica@ebd.csic.es 


\begin{abstract}
Seed dispersal by animals drives persistence and colonization of the majority of fleshy-fruited plants. Different factors have been identified as important in shaping patterns of seed deposition. These factors include habitat heterogeneity, movement patterns of frugivore species, and their feeding behavior. Most studies, however, have analysed the effect of one factor at the time, either with a modelling approach or from field observations. Here, we combine empirical data with spatially-explicit models to explore the contribution of habitat availability and patterns of frugivore post-feeding flight distances to the spatial patterns of seed dispersal.

We found that both factors, distance from the mother tree and microhabitat identity, were shaping those patterns. Our results show that seed dispersal is tremendously heterogeneous and complex in space. The observed seed shadow is not the result of a single process but instead an intricate combination of distance and habitat selection. We suggest that the apparent combination of processes results from the simultaneous effects of distinct functional groups of frugivores.
\end{abstract}

keywords: Taxus baccata L., plant-animal interaction, microhabitat selection, dispersal distance, Bayesian statistics 


\section{Introduction}

2 The establishment of new individuals is a critical step in plant population dynamics. 3 Indeed, the persistence of populations and the colonization of new patches are directly 4 conditioned by seed dispersal. In a vast majority of fleshy-fruited plant species, seed 5 dispersal requires the interaction with frugivorous animals (Herrera, 2002). Zoochory 6 is advantageous for plants in many ways. Frugivores allow the colonization of distant patches (Nathan, 2006; Wotton and Kelly, 2012), escape from herbivores and pathogens (Rice, 2002), and drive gene flow (Godoy and Jordano, 2001; Grivet et al., 2005; Dyer, 2007).

Due to their central role, mutualistic plant-frugivore interactions have received much attention. Empirical studies have shown that frugivores select among the available microhabitats in the landscape (Schupp, 1993; Graham, 2001; Holbrook and Smith, 2000; Spiegel and Nathan, 2009), which translates into strongly non-random, spatially structured, seed shadows (Fragoso, 1997; Jordano and Schupp, 2000; García et al., 2007a). Open habitats tend to be avoided by frugivores while conspecific or other fruiting trees are often preferred (Alcántara et al., 2000; Jordano et al., 2007; García et al., 2007b; Martínez et al., 2008; Clark et al., 2004). However, fruiting trees, conspecific or not, are not necessarily suitable sites for seed germination. They usually receive high seed densities (Jordano and Schupp, 2000; Martínez et al., 2008; Herrera and García, 2009; unpublished data) that are likely coupled to high predation rates (García et al., 2005). Moreover, density-dependent and maternal neighborhood effects (Janzen, 1970) potentially cancel positive effects of higher germination rates (Schupp and Fuentes, 1995; Calviño-Cancela, 2007; Sanz et al., 2009). Although we have a good understanding of the role of frugivores in the arrival of the seeds in suitable microhabitats for germination and potential seedling 
1 establishment (Cousens et al., 2008), our knowledge is still limited in terms of assessing the relative importance of different factors such as frugivores' movement patterns (Herrera and García, 2009, 2010), dispersal distance (Schurr et al., 2009), and habitat heterogeneity (García et al., 2009).

Collecting reliable empirical data to link frugivore behavior to seed dispersal patterns is a costly and difficult task (Carlo et al., 2007; Carlo and Morales, 2008). As a consequence, our understanding of the spatial component of seed dispersal at the population level remains poor and there is the need to develop and test mechanistic models of the process (Nathan and Muller-Landau, 2000; Carlo and Morales, 2008; Cousens et al., 2008; Côrtes and Uriarte, 2012). The bulk of theoretical studies have focused on resource-tracking behavior of frugivores (Lehouck et al., 2009; Carlo et al., 2007) or landscape characteristics (Morales and Carlo, 2006; Carlo and Morales, 2008, for spatial aggregation; Levey et al., 2008, for patch shapes).

Some studies have attempted to incorporate frugivores' preferences, although in a preliminary way. Russo et al. (2006) included resting sites as the only habitat preference in addition to resource tracking. However, empirical studies show that frugivores use the surrounding vegetation in a more complex way (Jordano and Schupp, 2000). Resource tracking is an important driver of frugivore movements at the regional and landscape scale (Kollmann, 2000), especially in landscapes where fruit resources are scarce or distributed in distant patches (Alcántara et al., 2000). Nonetheless, frugivore movements are influenced by other properties of the surrounding vegetation matrix (e.g., the presence of hubs, Carlo et al., 2007; isolated trees, Herrera and García, 2009).

A major measurable outcome of the seed dispersal process is the distance from the mother tree at which a seed is deposited. The probability density function of the location of seed deposition with respect to the source define the dispersal kernel of a population 
1 (Nathan and Muller-Landau, 2000). For this reason, the dispersal kernel is also commonly

2 used as a surrogate of seed deposition (Clark et al., 1999; Higgins and Cain, 2002; Spiegel and Nathan, 2009). Also, it might be shaped by the spatial availability of habitat and therefore highly context-dependent (Carlo, 2005; Schurr et al., 2008).

These previous studies have significantly advanced our understanding of specific mechanisms. What is still missing, however, is the complete picture of the interaction between dispersal agent behavior, landscape features, and seed deposition patterns. Little previous work has explored whether it is the microhabitat type or the distance from the source tree that influences bird foraging behavior, and thus seed deposition (but see Alcántara et al., 2000; Jordano and Schupp, 2000; Herrera and García, 2010). In this study, we focus on Taxus baccata L., a long-lived, slow-growing conifer, and its

avian seed dispersers to explore the extent to which landscape features, by modulating bird foraging behavior, drive seed-shadow patterns. We build spatially explicit models, parameterized from our field study, to answer the following questions: i) Do observed flight distances explain the spatial patterns of the seed shadow? ii) Is microhabitat availability a good predictor of spatial seed-shadow patterns? and iii) Are observed seed-shadows produced by a combination of distance and microhabitat availability? And if so, to what extent does each factor contribute to that spatial pattern?

\section{Material and methods}

\section{Species and study site}

The evergreen, non-resinous gymnosperm Taxus baccata L., the common yew, is a dioecious wind-pollinated tree (Thomas and Polwart, 2003; Sanz et al., 2009). It grows as an isolated or secondary forest tree from Norway to Northern Morocco. Embryos are protected by pseudobayes composed of a seed partially covered by a red and fleshy aril. 
1 Hereafter, for simplicity, we will just use the term fruit. The common yew relies princi2 pally on avian frugivores, especially Turdus spp. (Snow and Snow, 1988), for the dispersal of its seeds. By removing the surrounding aril, birds prevent fungal infection of the seeds and enhance seed germination (Heit, 1969; Fricke et al., 2013). Through their feeding behavior, birds set up the template for common yew population dynamics (Schupp and Fuentes, 1995).

The field study was conducted over two fruiting seasons, from August 2006 through December 2007, at the Barrerón de Escobarejos field site in the Sierra de Gredos, Spain $\left(40^{\circ} 12^{\prime} \mathrm{N}, 5^{\circ} 60^{\prime} \mathrm{W}\right.$, elevation ranges from $1300 \mathrm{~m}$ a.s.l. to $1400 \mathrm{~m}$ a.s.l.). The studied population grows under a continental Mediterranean climate in the southern limits of its geographical range. It is located in the upper limit of a semideciduous oak forest (Quercus pyrenaica) on a north-facing slope and extended over 13ha. It comprised 21 adult trees, 15 females and 6 males, distributed along seasonal streams surrounded by shrublands. Vegetation is dominated by tall and medium-sized shrubs, mainly Erica australis, E. arborea, Genista florida and Cytisus oromediterraneus, with a few spatiallyaggregated trees that produce fleshy fruits (Sorbus aucuparia, Ilex aquifolium and Taxus baccata L.) and non-fleshy fruits (Quercus pyrenaica and Alnus glutinosa). The highly fragmented landscape presents a rich mosaic of habitats at the local scale. Since the common yew is the dominant species at this site, and its disperser community is small, the local landscape configuration provides an adequate system to study seed dispersal in heterogeneous conditions.

\section{Seed sampling and feeding observations}

We defined six different types of microhabitats based on both soil type and vegetation cover: (1) "T. baccata female," beneath a female conspecific tree; (2) "shrubs," plant 
1 species $<1.50 \mathrm{~m}$ in height; (3) "fleshy-fruited trees," beneath trees other than the common 2 yew that produce fleshy fruits and were $>1.50 \mathrm{~m}$ in height; (4) "non-fleshy-fruited trees," 3 beneath trees that do not produce fleshy fruits and were $>1.50 \mathrm{~m}$ in height; (5) "open 4 ground," deep soil with thick vegetation cover (pasture) or with gravel under $25 \mathrm{~cm}^{2}$; (6) 5 "rocks," including stones on soil, boulders, and rock substrates of at least $25 \mathrm{~cm}^{2}$. We categorized types 1-4 as "covered" microhabitats and types 5-6 as "open" microhabitats.

$7 \quad$ We quantified the seedfall patterns via a stratified sampling by microhabitat. Because s of the presence of cattle and the absence of a fence in the study site, we used open quadrats of $0.5 \mathrm{~m} \times 0.5 \mathrm{~m}$ instead of seed traps albeit they might be prone to seed losses. A study by Sanz and Pulido (2013) in the same location showed that seed predation by rodents was overall homogenous between microhabitats (see also Matías et al., 2009, for similar results). Also, Wang et al. (2012) showed that the seeds of three of four studied tree species were eaten and left in situ. Although our sampling method might not have prevented seed losses, these previous studies demonstrate that, when they happened, they were likely of similar magnitude in all open-quadrats. In addition, various studies have shown that this sampling method provides reliable estimates of the amount of seeds dispersed (Martínez, 2007; Carlo et al., 2013; García et al., 2005, 2011).

The sampling scheme consisted of an even number of sampling points per microhabitat (when not constrained by microhabitat availability), each one being composed of two open quadrats located at a maximum distance of $0.5 \mathrm{~m}$ from each other. Hereafter and for simplicity, we will refer to each sampling point as a seed-plot. Seed-plots were checked every two weeks for the identification and count of fallen seeds. We were able to distinguish between dispersed seeds - smooth seeds without aril-and non-dispersed seeds - those with aril. To account for post-dispersal predation, seeds collected inside the seed-plots and showing signs of rodent predation were counted as part of the pool of 
dispersed seeds.

The female trees were unlikely to contribute equally to the overall seed rain of the study population. Existing studies have rather shown that bird visitation rates were correlated to fruit production (Blendinger et al., 2008; Vergara et al., 2010), therefore implying an heterogeneous contribution of individual mother trees. During the second fruiting season, in 2007, we estimated crop sizes by direct counts for all 15 female trees after all fruits had ripened, by late September. We counted the number of fruits left on the tree and removed by frugivores (by counting pedunculs) to estimate the total fruit yield. Depending on the size of the tree, we counted fruits in one quarter up to the entire canopy and multiplied accordingly to estimate the total crop size. Also, in both seasons studied, we counted the ripe fruits that had fallen underneath $T$. baccata female trees within the corresponding seed-plots. In 2007, the number of fruits fallen beneath a female tree was positively correlated with its fruit yield $\left(\mathrm{R}^{2}=0.7774, P<0.001\right)$. Based on the positive correlation found in 2007 between crop sizes and fallen fruits, we summed, for each female tree, the number of fallen fruits collected over the two years of study. From this value, $F_{i}$, we calculated the probability of being visited by birds, a surrogate of individual contribution to the total seed rain, for each mother tree (see the "Spatially-explicit models" section).

We conducted direct feeding observations on a total of 11 female trees (of the 15 total) over the two years of study; the remaining female trees did not produce fruits. Two-hour observation sessions were performed during the activity range of frugivores (8:30-10:30, 10:30-12:30 and 12:30-14:30) such that each tree was observed at least once during each period of time, for a total of 54 hours. During the observation sessions, we paid special attention to the bird's behavior and recorded the following data for each bird sighted whenever possible: (1) bird species; (2) total time spent at the tree; (3) number of fruits 
1 swallowed, if any; (4) exit flight distance; and (5) identity of first perch after leaving 2 the focal tree. We followed each individual bird from the moment it entered the focal tree until it stopped on a first perch or until it was out of view. Because the study site is dominated by small shrubs, we had a good visibility to determine the identity of the first perch after a bird had left a Taxus tree. The flight distances to the first perch were estimated visually and validated a posteriori.

$7 \quad$ Prior to bird observations all seed-plots and trees in the study population were mapped 8 (see the "Landscape structure" section for a description of the methodology). When flights 9 were recorded between any two georeferenced points, we compared afterwards the value estimated from direct observation with the actual euclidean distance. Moreover, to avoid distance estimates biased towards short distances, we accounted for birds that flew out of view ; these observations represented $9 \%$ of all the recorded distances. When in the field, we estimated that these birds had flown a minimum distance of $100 \mathrm{~m}$. We thus, picked a random distance between 100m and 350m (see Martínez et al., 2008 and Godoy and Jordano, 2001, for dispersal kernels estimates of a similar assemblage of species).

\section{Landscape structure}

Each T. baccata tree and seed-plot in our study site was georeferenced using a Leica GS20 differential GPS. Post-processing using Leica GisDataPro software allowed for an average precision of $0.5 \mathrm{~m}$. Original data in geographic coordinates were projected in UTM coordinates using Quantum GIS 1.0.2 Kore software.

Virtual boundaries were set on the landscape based on the aerial photograph of the study site such that all $T$. baccata trees and seed-plots were included. The resulting spatial lattice covered a $260 \mathrm{~m} \times 510 \mathrm{~m}$ area and was divided into $10 \mathrm{~m} \times 10 \mathrm{~m}$ cells. Specifically, we located the seed-plots - for which we characterized the microhabitat in the field - on 
1 the aerial photograph and visually classified the microhabitat types using those seed-plots

2 as a reference. Based on the criteria established, we identified on the aerial photograph 3 the microhabitats present in each cell of the lattice. We chose $100 \mathrm{~m}^{2}$ as the size of the cells 4 because it is small enough to reflect most of the microhabitat variability in our landscape. 5 Nonetheless, it is still too large to systematically assign a single microhabitat to each 6 cell. Therefore, cells were classified in terms of the relative proportion of the different microhabitats they contain. We will refer to the microhabitat composition of a cell as its microhabitat vector. The spatial lattice was also projected in UTM coordinates so that we knew which T. baccata trees and seed-plots were found within each cell.

\section{Spatially-explicit models}

\footnotetext{
We sought to compare the amount of seeds observed at the seed-plot level with simulated data to understand the processes that drive seed deposition and the potential spatial interplay between them. To do so, we built three models that simulated seed dispersal.

The first and second model simulated distance-based and habitat-based seed dispersal, respectively, while the third was a combination of both distance and habitat. All models were parametrized with the spatial information defined in the previous sub-sections: the spatial position and microhabitat vector of each lattice cell, the distribution of T. baccata trees, and the seed-plot locations. Fruit production, $F_{i}$, was assigned to individual female trees as explained previously.
}

\section{Distance-based model}

In the first model, based on distance, the arrival of a seed to a cell is determined by the seed-dispersal kernel. We approximated the dispersal kernel with a Weibull distribution with best-fit parameters estimated from empirically-observed flight distances (Fig. 1b). 
1 Since every flight was a random observation of full foraging sequence, we assume that unique flight distance data provide us with a reliable estimate of the distribution of flight distances. By doing so we did not account for the gut passage time of the different bird species involved in the dispersal of the seeds. However, these birds frequently regurgitate rather than defecate the seeds thus resulting in short time interval between feeding and dispersal events (Sorensen, 1984; Jordano and Schupp, 2000). Moreover, our fitted 7 Weibull distribution is consistent with the fat-tailed kernels typically found in the lit8 erature (Jordano and Schupp, 2000; Grivet et al., 2005; García et al., 2007a; Martínez 9 et al., 2008). Finally and most importantly, two studies conducted in southern Spain, at

the same study site, found similar seed dispersal kernels using either field observations (Jordano and Schupp, 2000) or molecular techniques (Godoy and Jordano, 2001).

In this model, a female tree is first selected according to its fruit production as follows:

$$
a_{i}=\frac{F_{i}}{\sum_{j=1}^{T} F_{j}},
$$

where $a_{i}$ is the probability of selecting mother tree $i, F_{i}$ is its fruit production, and the sum is over all $T$ mother trees. Next, the dispersal direction was picked uniformly at random and the dispersal distance was randomly selected from the parameterized Weibull distribution. Given the distance and direction, we directly determined in which cell the seed falls. In the event that the seed falls outside the boundaries of the landscape, we ignore it and disperse a new seed. In addition, to measure seed dispersal at the seed-plot scale, we use the probability $p_{s t}$ that a seed, once falling in a cell, landed in a seed-plot:

$$
p_{s t}=\frac{N_{t} A_{t}}{A_{c}},
$$

where $N_{t}$ is the number of seed-plots within the cell, $A_{t}$ is the area of a seed-plot $\left(0.5 \mathrm{~m}^{2}\right)$, 
1 and $A_{c}$ is the total area of the cell $\left(100 \mathrm{~m}^{2}\right)$. The simulation stopped when the sum of the 2 number of simulated seeds in the seed-plots equaled 5398, the total number of dispersed 3 seeds collected in our experiment over the two years studied.

\section{Habitat-based model}

5 In the second model, based on habitat selection, the arrival of a seed is determined by the 6 microhabitat type and its proportion within a cell. In this model, we used the pattern of 7 microhabitat selection by frugivores as a surrogate for seed deposition patterns (Fig. 1c).

8 Therefore, we estimated the proportion of flights to each microhabitat type directly from 9 field data and incorporated these proportions in the model. We first selected a tree 10 according to its fruit production from Eq. 1, just as above. Next, a microhabitat is picked 11 based on birds' selection:

$$
h_{i}=\frac{P_{i}}{\sum_{j=1}^{H} P_{j}},
$$

where $h_{i}$ is the probability of selecting microhabitat $i, P_{i}$ is the observed number of flights to microhabitat $i$, and the sum is over all $H$ microhabitats. From the subset of cells where the selected microhabitat is present, we chose one cell according to the fraction of that microhabitat that it contains. In doing so, we take into account that larger microhabitat patches will attract bird species more often. Finally, the probability $p_{s t}^{h}$ for a seed to fall both into a cell and into a seed-plot is given by:

$$
p_{s t}^{h}=\frac{N_{t}^{h} A_{t}}{P_{h} A_{c}},
$$

where $p_{s t}^{h}$ is the probability for a seed to be dispersed into a seed-plot of a particular microhabitat within a cell, $N_{t}^{h}$ is the number of seed-plots in that particular microhabitat 
1 within that cell, and $P_{h}$ is the proportion of the microhabitat within the cell. As before,

$2 A_{t}$ is the area of a seed-plot $\left(0.5 \mathrm{~m}^{2}\right)$, and $A_{c}$ is the total area of the cell $\left(100 \mathrm{~m}^{2}\right)$. Again, 3 the simulation stopped when the sum of the number of simulated seeds in the seed-plots 4 equaled 5398, the observed number of dispersed seeds.

\title{
5 Distance- and habitat-based model
}

6 In the third model, we combine the two previous models so that a seed falls into a cell 7 depending on both the microhabitat type available and the distance from the female $\approx$ tree. To explicitly account for the interaction between microhabitat and distance, we 9 estimate the microhabitat-specific seed-dispersal kernels from the corresponding subsets

\begin{abstract}
of exit flight distances. The microhabitats for which the seed-dispersal kernels were not statistically different were grouped (group1: open ground, rocks, and non-fleshy-fruited trees; group2: fleshy-fruited trees and shrubs; group3: T. baccata female trees).

In this model, a female tree is first picked according to its fruit production from Eq. 1 and a microhabitat is selected according to bird's selection from Eq. 3. Once the microhabitat is chosen, a distance is picked from the seed-dispersal kernel specific of that microhabitat. The cell where the seed will land is chosen from the cells containing the selected microhabitat and located at the selected distance. In the first two models, a seed was dispersed according to the distance from the source tree or the microhabitat type, whereas in this third model the two components are explicitly combined. The probability for a seed to land into both a cell and a seed-plot is calculated as in Eq. 4. As for the two previous models, the simulation stopped when the sum of the number of simulated seeds in the seed-plots equaled 5398, the observed number of dispersed seeds. Hereafter, this model will be referred to as the interaction model for simplicity.
\end{abstract}




\section{Data analyses}

2 We ran 10,000 replicates of each model and recorded the number of seeds per cell and per

3 seed-plot for each replicate. For each model replicate, we compared the simulated number

4 of seeds-per-seed-plot with the empirical number of seeds following:

$$
D_{o b s}=\sum_{i=1}^{n}\left(O_{i}-\bar{E}_{i}\right)^{2},
$$

5 where $i$ is the seed-plot, $O_{i}$ is the empirical number of seeds per seed-plot, $\bar{E}_{i}$ is the 6 mean simulated number of seeds per seed-plot, and the sum is over all $n$ seed-plots. We 7 then calculated $D_{\text {exp }}$ in a similar manner than in Eq. 5. That is, we used the simulated 8 number of seeds of a replicate instead of the empirical number of seeds per seed-plot in 9 our calculation. This procedure was repeated for each simulated replicate to obtain a

distribution of $D_{\text {exp }}$ values. If a model explains the observed data, the value $D_{\text {obs }}$ would fall within the $95 \%$ confidence interval of the $D_{\exp }$ distribution (D'Agostino and Stephens, 1986).

In addition, to estimate the overall fit of the model as described above, we quantified the goodness-of-fit on a seed-plot basis to account for the potential spatial heterogeneity in the prediction of the models. The probability of reproducing the empirical data at the seed-plot scale was given by:

$$
p_{i}=\frac{N_{i}^{o b s}}{N_{\text {sim }}}
$$

where $p_{i}$ is the probability of obtaining the empirical value among the simulated values for seed-plot $i, N_{i}^{o b s}$ is the number of times that the simulated value equals the observed value for seed-plot $i$, and $N_{\text {sim }}$ is the total number of simulated replicates. The model that has the highest probability best explained the observed value at that particular seed-plot 
1 compared to the other two models.

2 We used a nested-sampling algorithm to estimate the relative contribution of each 3 process to the overall seed shadow (Sivia and Skilling, 2006). To do so, we first made use 4 of the likelihood of any candidate model $M$ defined as:

$$
L(M)=\prod_{i=1}^{n} p_{i}^{M},
$$

5 where $L(M)$ is the likelihood of model $M$ and $p_{i}^{M}$ is the probability of reproducing the 6 empirical data within seed-plot $i$ (calculated as in Eq. 6) for model $M$. In the nestedsampling procedure, we simulated seed dispersal anew but, instead of running a single model many times, we selected a different seed-dispersal rule for each seed (i.e., dispersal based on distance-only, microhabitat-only, or both). The algorithm starts with arbitrary initial probabilities assigned to the three models. Under such a model, a seed-dispersal rule is first picked according to its probability and the seed dispersed according to the corresponding model. The nested-sampling algorithm then explores the space of possible combinations while attempting to maximize the likelihood. As a result, we are able to directly estimate the optimal combination of the three dispersal mechanisms at the seed-scale as well as obtain Bayesian estimates of the confidence intervals around this combination.

\section{${ }_{17}$ Results}

\section{Field data}

Based on the microhabitat vector assigned to each cell of the spatial lattice, we estimated the availability of each microhabitat type. The landscape was dominated by open areas (open ground: 40.5\%; rocks: 9.4\%) and low shrubs (43.3\%). Trees represented just 7\% 
1 of the study site (non-fleshy fruited trees: 6.2\%; fleshy-fruited trees: $0.2 \%$; T. baccata female trees $0.4 \%$ )

The frugivore guild associated with the common yew in the study population was composed of a few species. Three bird species fed most frequently on T. baccata trees (Table 1): Blackbirds (Turdus merula), Mistle Thrushes (T. viscivorus), and Blackcaps (Sylvia atricapilla). Ring Ouzels (T. torquatus) and Eurasian Jays (Garrulus glandarius) were observed only occasionally and their contribution to the seed shadow is likely to be marginal. One seed predator, the Great Tit (Parus major), was present, although it only damages a small fraction of fruits (Table 1).

Individuals of $T$. viscivorus consumed the highest mean number of fruits, followed by T. merula and S. atricapilla (Table 1). However, since only a few individuals of T. viscivorus and S. atricapilla were observed feeding on T. baccata trees, 13 and four respectively, most of the seeds were dispersed by T. merula. All of the species spent substantial time perching per visit in yew trees and showed high variability in the mean number of fruits consumed per individual. With the exception of T. viscivorus, that was absent in 2006, all other species were present in both years. Despite some differences in species traits (e.g., meal size, flight distances), we considered the frugivore guild as a whole in order to increase the size of our dataset. Analyses were therefore conducted at the guild level.

During the two years of study, a total of 337 exit flights were recorded from direct bird observations. Slightly more than $50 \%$ of those flights were consecutive to a feeding event. From those, $89 \%$ were from Turdus merula. Typically, Turdus merula individuals were observed feeding on a Taxus tree, then flying to a close tree and flying back to the first Taxus tree, thus remaining in the vicinity of the source tree for a substantial amount of time (personal observation). The foraging behavior of T. merula coupled with 
1 short regurgitation times (Sorensen, 1984) lead to a high probability of seed deposition under the source tree or in its immediate vicinity. Indeed, the resulting flight distances distribution was strongly skewed towards short distances (Jordano and Schupp, 2000; Martínez et al., 2008). We fitted flight distances data to a Weibull distribution (global seed-dispersal kernel: scale $=24.75$ and shape $=0.843$, Fig. 1b; group1 seed-dispersal kernel: scale $=17.09$ and shape $=0.829$; group2 seed-dispersal kernel: scale $=28.81$ and shape $=1.072 ;$ group3 seed-dispersal kernel: scale $=6.92$ and shape $=2.029)$.

A total of $93.3 \%$ of the exit flights were to microhabitats with vegetation cover. We analyzed the frequencies in a number-of-flights $\times$ microhabitat contingency table, controlling for microhabitat availability, to assess selection patterns in the choice of the first perch. We estimated the significance of individual residual frequencies with the chi-square distribution with the global degrees of freedom. The frugivore guild showed a marked tendency to use particular microhabitat types $\left(\chi^{2}=1156\right.$, df $=5, P<0.001$, Fig. 1c), especially trees independent of whether they produce fleshy fruits (conspecific or not) or non-fleshy fruits.

\section{Simulations}

Each of the three models provided seed-dispersal simulations at the landscape and seedplot scale. All three models produced distinct overall patterns of seed density (Fig. 2). In the distance-based model, most seeds were dispersed around the female trees, leading to a clumped seed shadow. The habitat-based generated a more homogeneous seed-shadow pattern since almost all of the cells received seeds, albeit in variable proportions. The interaction model produced a pattern that most closely resembles that of the distancebased model. Large areas of the landscape received low seed densities; however, the resulting seed shadow was less symmetric since it adjusted more to the shape of preferred 
1 habitat patches.

2 The overall fit of each model to the empirical data was assessed based on the distance $D$ from Eq. 5. None of the three models was a strong predictor of the global distribution 4 of the number of seeds per plot; that is, the probability of the models generating a similar 5 seed shadow was very small $(P<0.001$ for all models). Nevertheless, since the models 6 produced spatially-heterogeneous patterns, we checked for the goodness-of-fit on a seed7 plot by seed-plot basis.

The probability to generate the empirical value was highly variable between seed-plots (Fig. 3). The habitat-based model in general performed rather poorly. It predicted the observed number of seeds with a probability of at least 0.5 in only $3 \%$ of the seed-plots. The distance-based and interaction models produced more similar results to each other. In the distance-based model, the empirical number of seeds was predicted with a probability of at least 0.5 and 0.8 in a larger fraction of seed-plots than in the interaction model (25\% and $18 \%$, respectively, for the distance-based model; $24 \%$ and $15 \%$ for the interaction model). At higher thresholds, however, the interaction model performed slightly better. It predicted the empirical number of seeds with a probability of at least 0.9 in $12 \%$ of the seed-plots while this proportion drops to $5 \%$ for the distance-based model. We identified the best individual model (i.e., the one with the highest probability) on a seed-plot basis (Fig. 4). Although a model was assigned to every seed-plot, this does not necessarily imply a good fit of that model. As before, the distance-based model has the highest number of seed-plots associated (45\%). The habitat-based model is associated with $23 \%$ of the seed-plots and $32 \%$ are associated with the interaction-based model. The subsets of seed-plots best explained by each model did not display any clear spatial pattern (Fig. 4).

To that point, we implicitly assume that all the seeds within a seed-plot were dispersed by the same process (distance, habitat, or a combination of both). However, those seeds 
1 may not necessarily have been dispersed by the same process which could explain the lack of concluding results in the previous analyses (Figs. 3 and 4). Using Eq. 7, we explored the combination of the three processes (distance, habitat, and interaction ) that would best fit the empirical data at the seed-level. The combination that maximizes the log-likelihood 5 (i.e., that provides the best fit to the empirical data) was one in which $99 \%( \pm 0.4)$ of the 6 seeds were dispersed based on the interaction between distance and habitat, $1 \%( \pm 0.006)$ 7 based on microhabitat selection and no seeds were dispersed based on distance alone.

\section{Discussion}

Seed dispersal is a spatially-complex and multi-agent process (Nathan and Muller-Landau, 2000; Alcántara et al., 2000; Jordano et al., 2007). Understanding the contribution of the different agents involved and how they interact with the local spatial context is far from straightforward. Here, we have incorporated fine-scale, geographic information into mechanistic seed dispersal models to disentangle the role of landscape features in determining seed fate. We successively tested the role of distance from the mother tree, the role of microhabitat type and finally the role of the interaction between the two. The three models successively tested for increasing complexity in the potential mechanisms that generate seed-shadow patterns.

Overall, none of the models explained the empirical seed-shadow patterns demonstrably better than the others, despite the contrasting output they produced (Fig. 2). However, it is important to note that the lack of fit was not homogeneous across seedplots (Fig. 3). The subset of seed-plots located on the west side and southeast corner of the landscape remained largely unexplained. In contrast, the subsets of seed-plots in the center and on the east side of the landscape were generally slightly better predicted by the distance-based model (Fig. 3). 
Interestingly enough, the seed-plots that were best explained in all scenarii - in the center and east side - tended to be located at a considerable distance from the mother trees with the highest fruit production - on the west side (Figs. 1 and 3). In our field experiment, this subset of seed-plots received a small amount of seeds. Indeed, the distance and interaction models adjusted well to those seed-plots, suggesting that they can predict where the seeds will not be dispersed in the landscape. Surprisingly, the habitatbased model performed rather poorly. Given the frugivorous birds' avoidance of open habitats, pointed out in many studies (Alcántara et al., 2000; Jordano and Schupp, 2000; Bartuszevige and Gorchov, 2006; Martínez et al., 2008), we expected that at least the avoided habitat patches would be well-predicted by the model. The spatial patterns in the goodness-of-fit of the three models suggest that a simple process, such as distance, might explain low seed densities away from the source tree, while more complex processes might drive seed deposition at a local scale.

The nested-sampling analysis reveals that, in the best-fit scenario, $99 \%$ of the seeds were dispersed by a process resulting from the interaction between the distance from the source tree and the microhabitat type and, most interestingly, that no seeds were dispersed by a process involving distance alone. This analysis, at the seed-level, highlights that each seed within a landscape might be dispersed by a unique seed-specific dispersal process resulting from the interaction between maternal tree location, bird species' identity, and microhabitat type.

The failure of the three models in predicting the spatial patterns of seed deposition could be a methodological bias. The method that we used to fit the observed flight distances might not have accurately estimated the true dispersal kernel (Robledo-Arnuncio and García, 2007). Nonetheless, as discussed previously, the models mostly failed to predict the number of dispersed seeds in the immediate vicinity of the female trees. This 
1 suggests that, if distance was in fact the process driving seed deposition, we would have underestimated local dispersal. Although a finer estimate of the dispersal kernel could have quantitatively improved our results, they might have remained qualitatively similar. $4 \quad$ A possible explanation of the apparent spatial asymmetry of the fit of the models could 5 be the confounding effects of different functional groups of frugivores (Martínez et al., 6 2008). We can distinguish the behavior of $S$. atricapilla and T. merula on one hand, and 7 T.viscivorus on the other. Sylvia atricapilla is an abundant and regular wintering species in Spain (Jordano and Herrera, 1981) while T. merula is a resident and territorial species 9 (Greenwood and Harvey, 1978). Both species, however, display a similar movement range (mostly within 50m, personal observation) and short gut passage time (Jordano, 1987, for S. atricapilla, Sorensen, 1984, for T. merula). We rarely observed these species flying through open areas. They might thus contribute to the seed shadow in the immediate proximity of the female trees. Moreover, T. merula individuals prefer to remain beneath the canopy cover and use some trees as roosting sites; this likely translates into nonrandom, directed seed deposition.

Turdus viscivorus, on the other hand, is a migrant species. Although resident populations were present in the area, we did not observe such population at our study site. Individuals typically fly much longer distances and preferentially select tall trees for perching (Jordano and Schupp, 2000; Jordano et al., 2007). We frequently observed individuals flying out of view but rarely to the other side of the population (west side of the landscape). Due to this asymmetric use of the landscape, T. viscivorus might have dispersed the seeds of only a subset of the female trees. Furthermore, T. merula, S. atricapilla, and T. viscivorus display distinct flight distance distributions (Jordano et al., 2007; Martínez et al., 2008). As a consequence, applying different dispersal kernels to individual mother trees, depending on the frugivore species that visit them, may possibly improve the fit of 
1 our models to the observed data.

2 The models implicitly assume that microhabitat selection is the only factor caus3 ing anisotropous movements of birds. Nevertheless, landscape elements such as isolated 4 trees (Herrera and García, 2009), food resources (Graham, 2001) or topographic variation 5 (Westcott, 1997) may also determine anisotropous movement patterns. The existence 6 of preferred elements in the landscape for perching or feeding, also called hubs, is a 7 probable cause of the variation in the goodness-of-fit at the seed-plot level (Carlo et al., 2007). Marked directionality, actually observed in the studied population (personal observation), is likely to create a non-uniform seed deposition within the studied landscape (García et al., 2007a; Carlo et al., 2013).

In the studied population, yew female trees displayed highly heterogeneous crop sizes. Indeed, two female trees located in the central area of the landscape did not produce fruits at all over the two studied years (Fig. 1a), probably due to pollen limitation (Sanz, 2008). From the frugivore's perspective, these two female trees are similar to the other non fleshy-fruited trees in the population. Indeed, because these female trees failed in acting as stepping stones (Herrera and García, 2009) and because there are no corridors (Levey et al., 2005), the east and west vegetation patches might not be functionally connected. In fact, birds are likely to forage within distinct vegetation patches and only rarely flew from one patch to the other (see Graham, 2001, for the cost-distance hypothesis). Our study site might not be a single population, but rather two patches displaying distinct seed dispersal dynamics.

In this study, we have developed a mechanistic spatially-explicit model to explore the seed-dispersal process in a real ecological context. The incorporation of spatial data highlights the complexity of such a process. Despite the patterns that have emerged from theoretical studies, predicting what actually happens in nature remains a difficult task. Nathan 
1 and Muller-Landau (2000) highlighted the necessity for more studies testing "predictions 2 based on disperser behavior against field data." To our knowledge, studies integrating empirical data of frugivore movements and seed-shadow patterns with spatially-explicit mechanistic models are scarce (but see Levey et al., 2005, Morales et al., 2013). Although simple, these models are a first step towards a better understanding of the complexity of interactions taking place in natural ecosystems. This study underlines the crucial need 7 for integrated approaches to unravel the role of frugivores in shaping spatial patterns of 8 plant populations and to move from local to global scales.

\section{- Acknowledgements}

We thank Pedro Jordano, Daniel García, Miguel Ángel Fortuna, Luis José Gilarranz, Eugene Schupp and two anonymous reviewers for valuable comments about the manuscript. Manolo Carrión helped us to process the seeds and provided support from the beginning of this study. Fernando Pulido gave valuable suggestions about the experimental design of the study. The Universidad de Extremadura - Escuela de Ingeniería Técnica Forestal provided us with off road vehicles to perform field work. Funding was provided by the European Heads of Research Councils, the European Science Foundation, and the EC Sixth Framework Programme through a European Young Investigator Award and an ERC's Advanced Grant (J.B.), a CSIC-JAE Postdoctoral fellowship from the Consejo Superior de Investigaciónes Científicas (to D.B.S.), and the Consejera de Agricultura y Medio Ambiente of the Junta de Extremadura (to R.S.). 


\section{References}

Alcántara, J. M., Rey, P. J., Valera, F. and Sánchez-Lafuente, A. M. 2000. Factors shaping the seedfall pattern of a bird-dispersed plant. - Ecology 81(7): 1937-1950.

Bartuszevige, A. M. and Gorchov, D. L. 2006. Avian seed dispersal of an invasive shrub. Biological Invasions 8: 1013-1022.

Blendinger, P. G., Loiselle, B. A. and Blake, J. G. 2008. Crop size, plant aggregation, and microhabitat type affect fruit removal by birds from individual melastome plants in the Upper Amazon. - Oecologia 158(2): 273-283.

Calviño-Cancela, M. 2007. Seed and microsite limitations of recruitment and the impacts of post-dispersal seed predation at the within population level. - Plant Ecology 192: $35-44$.

Carlo, T. A. 2005. Interspecific neighbors change seed dispersal patterns of an aviandispersed plant. - Ecology 86(9): 2440-2449.

Carlo, T. A., Aukema, J. E. and Morales, J. M. 2007. Plant-frugivore interactions as spatially explicit networks: integrating frugivore foraging with fruiting plant spatial patterns. - In: Dennis, A., Schupp, E. and Wescott, D. (eds.), Seed Dispersal: Theory and its application in a Changing World. CABI, Oxon, UK., pp. 369-390.

Carlo, T. A., García, D., Martínez, D., Gleditsch, J. and Morales, J. M. 2013. Where do seeds go when they go far? Distance and directionality of avian seed dispersal in heterogeneous landscapes. - Ecology 94(2): 301-307.

Carlo, T. A. and Morales, J. M. 2008. Inequalities in fruit-removal and seed dispersal: 
consequences of bird behaviour, neighbourhood density and landscape aggregation. Journal of Ecology 96: 609-618.

Clark, C. J., Poulsen, J. R., Connor, E. F. and Parker, V. T. 2004. Fruiting trees as dispersal foci in a semi-deciduous tropical forest. - Oecologia 139(1): 66-75.

Clark, J. S., Silman, M., Kern, R., Macklin, E. and Hillerislambers, J. 1999. Seed dispersal near and far: patterns accross temperate and tropical forests. - Ecology 80: 1475-1494.

Côrtes, M. C. and Uriarte, M. 2012. Integrating frugivory and animal movement: a review of the evidence and implications for scaling seed dispersal. - Biological Reviews .

Cousens, R., Dytham, C. and Law, R. 2008. Dispersal in plants, a population perspective. - Oxford University Press, Oxford.

D'Agostino, R. B. and Stephens, M. A. 1986. Goodness-of-Fit Techniques. - Marcel Kekker, Inc.

Dyer, R. J. 2007. Powers of discerning: challenges to understanding dispersal processes in natural populations. - Molecular Ecology 16: 4881-4882.

Fragoso, J. M. V. 1997. Tapir-generated seed shadows: scale-dependent patchiness in the amazon rain forest. - Journal of Ecology 85(4): 519-529.

Fricke, E. C., Simon, M. J., Reagan, K. M., Levey, D. J., Riffell, J. A., Carlo, T. A. and Tewksbury, J. J. 2013. When condition trumps location: seed consumption by fruit-eating birds removes pathogens and predator attractants. - Ecology Letters .

García, C., Jordano, P., Arroyo, J. M. and Godoy, J. A. 2009. Maternal genetic correlations in the seed rain: effects of frugivore activity in heterogeneous landscapes. Journal of Ecology 97: 1424-1435. 
García, C., Jordano, P. and Godoy, J. A. 2007a. Contemporary pollen and seed dispersal in a Prunus mahaleb population: patterns in distance and direction. - Molecular Ecology 16(9): 1947-1955.

García, D., Martínez, I. and Obeso, J. R. 2007b. Seed transfer among bird-dispersed trees and its consequences for post-dispersal seed fate. - Basic and Applied Ecology 8: $533-543$.

García, D., Obeso, J. R. and Martínez, I. 2005. Spatial concordance between seed rain and seedling establishment in bird-dispersed trees: does scale matter?. - Journal of Ecology 93: 693-704.

García, D., Zamora, R. and Amico, G. C. 2011. The spatial scale of plant-animal interactions: effects of resource availability and habitat structure. - Ecological Monographs 81(1): 103-121.

Godoy, J. A. and Jordano, P. 2001. Seed dispersal by animals: exact identification of source trees with endocarp DNA microsatellites. - Molecular Ecology 10(9): 2275-2283.

Graham, C. H. 2001. Factors influencing movement patterns of keel-billed toucans in a fragmented tropical landscape in southern mexico. - Conservation Biology 15: 17891798.

Greenwood, P. J. and Harvey, P. H. 1978. Foraging and territory utilization of blackbirds (Turdus merula) and song thrushes (Turdus philomelos). - Animal Behaviour 26: 12221236.

Grivet, D., Smouse, P. E. and Sork, V. L. 2005. A novel approach to an old problem: tracking dispersed seeds. - Molecular Ecology 14(11): 3585-3595. 
Heit, C. E. 1969. Propagation from seed. Part 18: testing and growing seeds of popular Taxus forms. - American Nursery-man 15 January: 10-11, 118-128.

Herrera, C. M. 2002. Seed dispersal by vertebrates. - In: Herrera, C. M. and Pellmyr, O. (eds.), Plant-Animal Interactions: An Evolutionary Approach. Blackwell Science, Oxford, UK, pp. 185-208.

Herrera, J. M. and García, D. 2009. The role of remnant trees in seed dispersal through the matrix: being alone is not always so sad. - Biological Conservation 142: 149-158.

- 2010. Effects of forest fragmentation on seed dispersal and seedling establishment in ornithochorous trees. - Conservation Biology 24: 1089-1098.

Higgins, S. I. and Cain, M. L. 2002. Spatially realistic plant metapopulation models and the colonization-competition trade-off. - Journal of Ecology 90: 616-626.

Holbrook, K. M. and Smith, T. B. 2000. Seed dispersal and movement patterns in two species of Ceratogymna hornbills in a West African tropical lowland forest. - Oecologia 125: $249-257$.

Janzen, D. H. 1970. Herbivores and the number of tree species in tropical forests. - The American Naturalist 104: 501-524.

Jordano, P. 1987. Frugivory, external morphology and digestive system in mediterranean sylviid warblers Sylvia spp. - Ibis 129: 175-189.

Jordano, P., García, C., Godoy, J.-A. and Garcia-Castaño, J.-L. 2007. Differential contribution of frugivores to complex seed dispersal patterns. - Proceedings of the National Academy of Sciences of the United States of America 104(9): 3278-3282. 
Jordano, P. and Herrera, C. M. 1981. The frugivorous diet of blackcap populations Sylvia atricapilla wintering in southern spain. - Ibis 123: 502-507.

Jordano, P. and Schupp, E. 2000. Seed disperser effectiveness: the quantity component and patterns of seed rain for Prunus mahaleb. - Ecological Monographs 70: 591-615.

Kollmann, J. 2000. Dispersal of fleshy-fruited species: a matter of spatial scale?. - Perspectives on Plant Ecology 3(1): 29-51.

Lehouck, V., Spanhove, T., Vangestel, C., Cordeiro, N. J. and Lens, L. 2009. Does landscape structure affect resource tracking by avian frugivores in a fragmented Afrotropical forest?. - Ecography 32: 789-799.

Levey, D. J., Bolker, B. M., Tewksbury, J. J., Sargent, S. and Haddad, N. M. 2005. Effects of landscape corridors on seed dispersal by birds. - Science 309(5731): 146-148.

Levey, D. J., Tewksbury, J. J. and Bolker, B. M. 2008. Modelling long-distance seed dispersal in heterogeneous landscapes. - Journal of Ecology 96: 599-608.

Martínez, I. 2007. Interacciones planta-animal en bosques templados de la Codillera Cantbrica. Ph.D. thesis, Universidad de Oviedo.

Martínez, I., García, D. and Obeso, J. R. 2008. Differential seed dispersal patterns generated by a common assemblage of vertebrate frugivores in three fleshy-fruited trees. Ecoscience 15: 189-199.

Matías, L., Mendoza, I. and Zamora, R. 2009. Consistent pattern of habitat and species selection by post-dispersal seed predators in a Mediterranean mosaic landscape. - Plant Ecology 203(1): 137-147. 
Morales, J. M. and Carlo, T. A. 2006. The effects of plant distribution and frugivore density on the scale and shape of dispersal kernels. - Ecology 87(6): 1489-1496.

Morales, J. M., García, D., Martínez, D., Rodriguez-Pérez, J. and Herrera, J. M. 2013. Frugivore Behavioural Details Matter for Seed Dispersal: A Multi-Species Model for Cantabrian Thrushes and Trees. - PloS one 8(6): e65216.

Nathan, R. 2006. Long-distance dispersal of plants. - Science 313: 786-788.

Nathan, R. and Muller-Landau, H. C. 2000. Spatial patterns of seed dispersal, their determinants and consequences for recruitment. - Trends in Ecology and Evolution 15: $278-285$.

Rice, P. W. 2002. Species interactions and the evolution of biodiversity. - In: Herrera, C. M. and Pellmyr, O. (eds.), Plant-Animal Interactions: An Evolutionary Approach. Blackwell Science, Oxford, UK, pp. 3-25.

Robledo-Arnuncio, J. J. and García, C. 2007. Estimation of the seed dispersal kernel from exact identification of source plants. - Molecular Ecology 16: 5098-5109.

Russo, S. E., Portnoy, S. and Augspurger, C. K. 2006. Incorporating animal behavior into seed dispersal models: implications for seed shadows. - Ecology 87(12): 3160-3174.

Sanz, R. 2008. Limitaciones de la regeneración en poblaciones marginales de Taxus baccata y Betula alba en ambientes mediterráneos. Ph.D. thesis, Universidad de Plasencia, Plasencia.

Sanz, R. and Pulido, F. 2013. Post-dispersal seed depletion by rodents in marginal populations of yew (Taxus baccata): consequences at geographical and local scales.. - Plant Species Biology p. accepted. 
Sanz, R., Pulido, F. and Nogués-Bravo, D. 2009. Predicting mechanisms accross scale: amplified effects of abiotic constraints on the recruitment of yew Taxus baccata. - Ecography 32: 993-1000.

Schupp, E. W. 1993. Quality, quantity and the effectiveness of seed dispersal by animals. Vegetatio 107/108: 15-29.

Schupp, E. W. and Fuentes, M. 1995. Spatial patterns of seed dispersal and the unification of plant population ecology. - Ecoscience 2: 267-275.

Schurr, F. M., Spiegel, O., Steinitz, O., Trakhtenbrot, A., Tsoar, A. and Nathan, R. 2009. Long-distance seed dispersal. - In: Annual Plant Reviews Volume 38: Fruit Development and Seed Dispersal. Wiley-Blackwell, pp. 204-237.

Schurr, F. M., Steinitz, O. and Nathan, R. 2008. Plant fecundity and seed dispersal in spatially heterogeneous environments: models, mechanisms and estimation. - Journal of Ecology 96: 628-641.

Sivia, D. S. and Skilling, J. 2006. Data analysis: A bayesian tutorial. - Oxford University Press, Oxford.

Snow, B. K. and Snow, D. W. 1988. Birds and Berries. - Waterhouses: T. \& A.D. Poyser.

Sorensen, A. E. 1984. Nutrition, energy and passage time: experiments with fruit preference in european blackbirds (Turdus merula). - Journal of Animal Ecology 53: 545-557.

Spiegel, O. and Nathan, R. 2009. Incorporating dispersal distance into the disperser effectiveness framework: frugivorous birds provide complementary dispersal to plants in a patchy environment. - Ecology Letters 10: 718-728. 
Thomas, P. A. and Polwart, A. 2003. Taxus baccata L. - Journal of Ecology 91: 489-524.

Vergara, P. M., Smith, C., Delpiano, C. A., Orellana, I., Gho, D. and Vazquez, I. 2010. Frugivory on Persea lingue in temperate Chilean forests: interactions between fruit availability and habitat fragmentation across multiple spatial scales. - Oecologia 164(4): 981-991.

Wang, B., Wang, G. and Chen, J. 2012. Scatter-hoarding rodents use different foraging strategies for seeds from different plant species. - Plant Ecology 213(8): 1329-1336.

Westcott, D. A. 1997. Lek locations and patterns of female movement and distribution in a Neotropical frugivorous bird. - Animal Behaviour 53(2): 235-247.

Wotton, D. M. and Kelly, D. 2012. Do larger frugivores move seeds further? Body size, seed dispersal distance, and a case study of a large, sedentary pigeon. - Journal of Biogeography 39(11): 1973-1983. 


\section{Figure captions}

Figure 1: Empirical observations used to parametrize the seed dispersal models. a) Aerial photograph of the study site showing the location of the T. baccata female trees. Circle size is proportional to the fruit production of each tree. The dotted line represents the boundaries of the spatial lattice used in the three models. b) Frequency distribution of flight distances collected from direct observation in the field. The data were fit to a Weibull distribution (solid line). c) Residuals of a contingency-table analysis of bird flights to microhabitat type, all species pooled. Individual bars represent residual frequencies and significant positive residuals indicate microhabitats favored while significant negative residuals indicate microhabitats avoided. ${ }^{\star} P<0.05$;

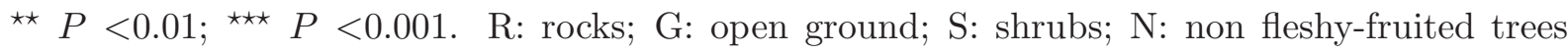
(including T. baccata male trees); F: fleshy-fruited trees (excluding T. baccata female trees); TF: T. baccata female trees.

Figure 2: Simulated seed densities across the landscape for the three models described in the text. Each panel represents one realization of the model and the color of the cells indicates high (dark green) or low (white) seed density probability. The black dots show the location of the female trees within the landscape. a) Distance-based seed dispersal model; b) Habitatbased seed dispersal model; c) Distance- and habitat-based seed dispersal model. It is visually apparent that the different models lead to distinct seed shadows.

Figure 3: Model goodness-of-fit at the seed-plot level. Boxes represent the seed-plots of the field experiment and the colorbar corresponds to the probabilities that the model generates the observed number of seeds, among all simulated replicates (10,000). a) Distance-based seed dispersal model; b) Habitat-based seed dispersal model; c) Distance and habitat-based seed dispersal model. The different models are able to explain well distinct subsets of seed-plots. 
Figure 4: Best-fit model on a seed-plot basis. Colors indicate the model with the highest probability of reproducing the observed number of seeds. Each model best predicts a comparable number of seed-plots. Interestingly, there is little apparent spatial organization of the model differences. 
Table 1: Visit frequencies, meal size, and visit duration of main seed dispersers of T. baccata.

\begin{tabular}{lllll}
\hline Bird species & Perching ${ }^{(1)}$ & Handling fruits ${ }^{(2)}$ & N fruits ${ }^{(3)}$ & Visit duration $^{(4)}$ \\
\hline Seed dispersers & & & & \\
Turdus merula & $0.62(108)$ & $0.87(158)$ & $3.66( \pm 2.75)$ & $2.0[1.0-3.0]$ \\
Turdus viscivorus & $0.04(14)$ & $0.07(13)$ & $5.50( \pm 3.90)$ & $5.0[1.4-5.0]$ \\
Sylvia atricapilla & $0.04(5)$ & $0.02(4)$ & $2.38( \pm 1.03)$ & $5.0[1.3-5.0]$ \\
Other species & $0.02(1)$ & $0.01(2)$ & $0.75( \pm 0.35)$ & - \\
Seed predator & & & & \\
Parus major & $0.28(27)$ & $0.03(5)$ & $1.10( \pm 0.55)$ & $1.0[0.5-1.3]$ \\
\hline
\end{tabular}

\footnotetext{
${ }^{1}$ Relative visit frequencies to T. baccata trees without feeding and number of individuals (in parentheses).

${ }^{2}$ Relative visit frequencies to $T$. baccata trees with feeding and number of individuals (in parentheses).

${ }^{3}$ Number of fruits handled per visit and per individual (excluding individuals only perching), mean $\pm 1 \mathrm{SE}$ (in parentheses)

${ }^{4}$ Mode [25-75\% quantiles], time in minutes.

${ }^{\dagger}$ Garrulus glandarius and Turdus torquatus
} 
Figure 1

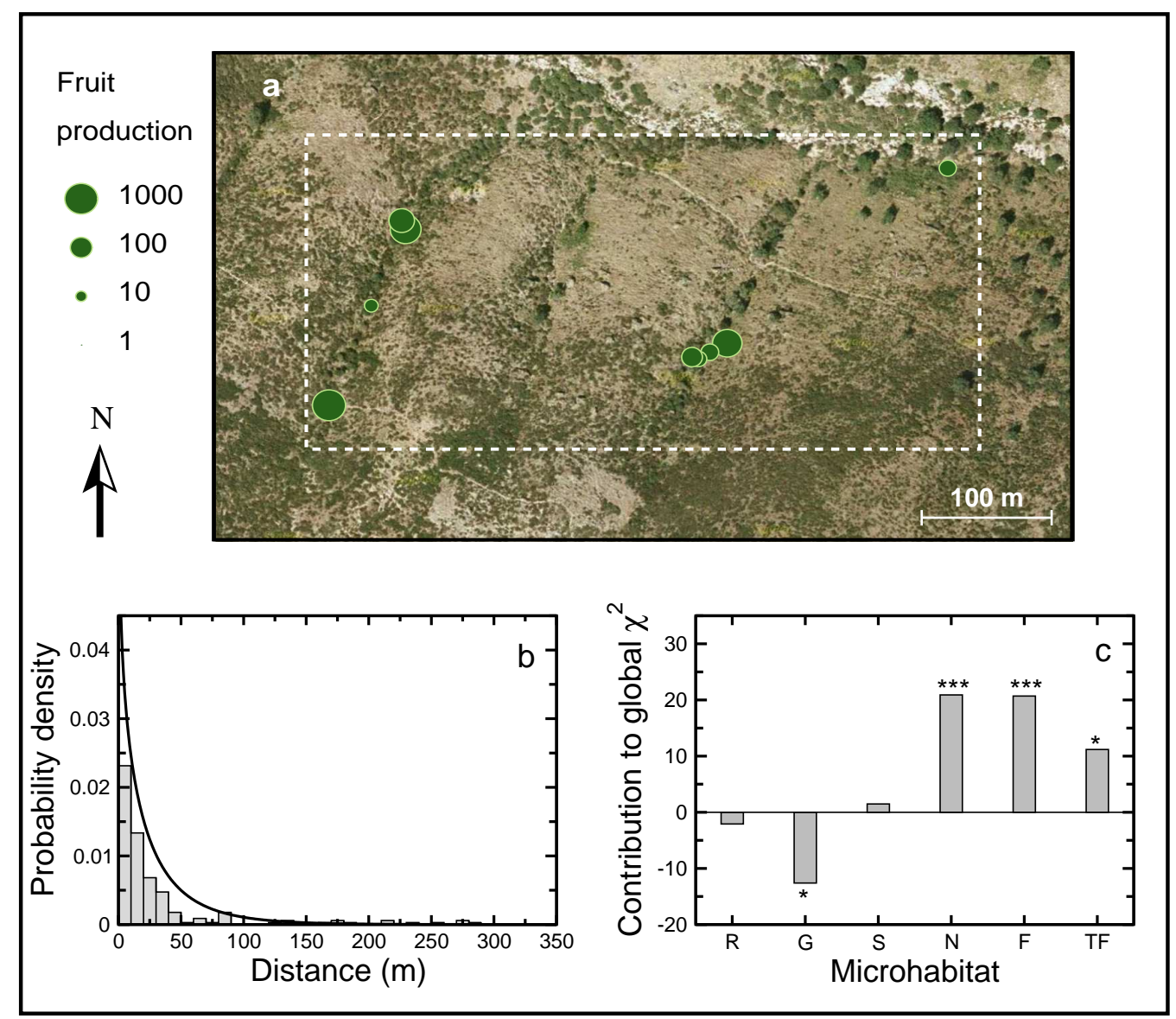


Figure 2

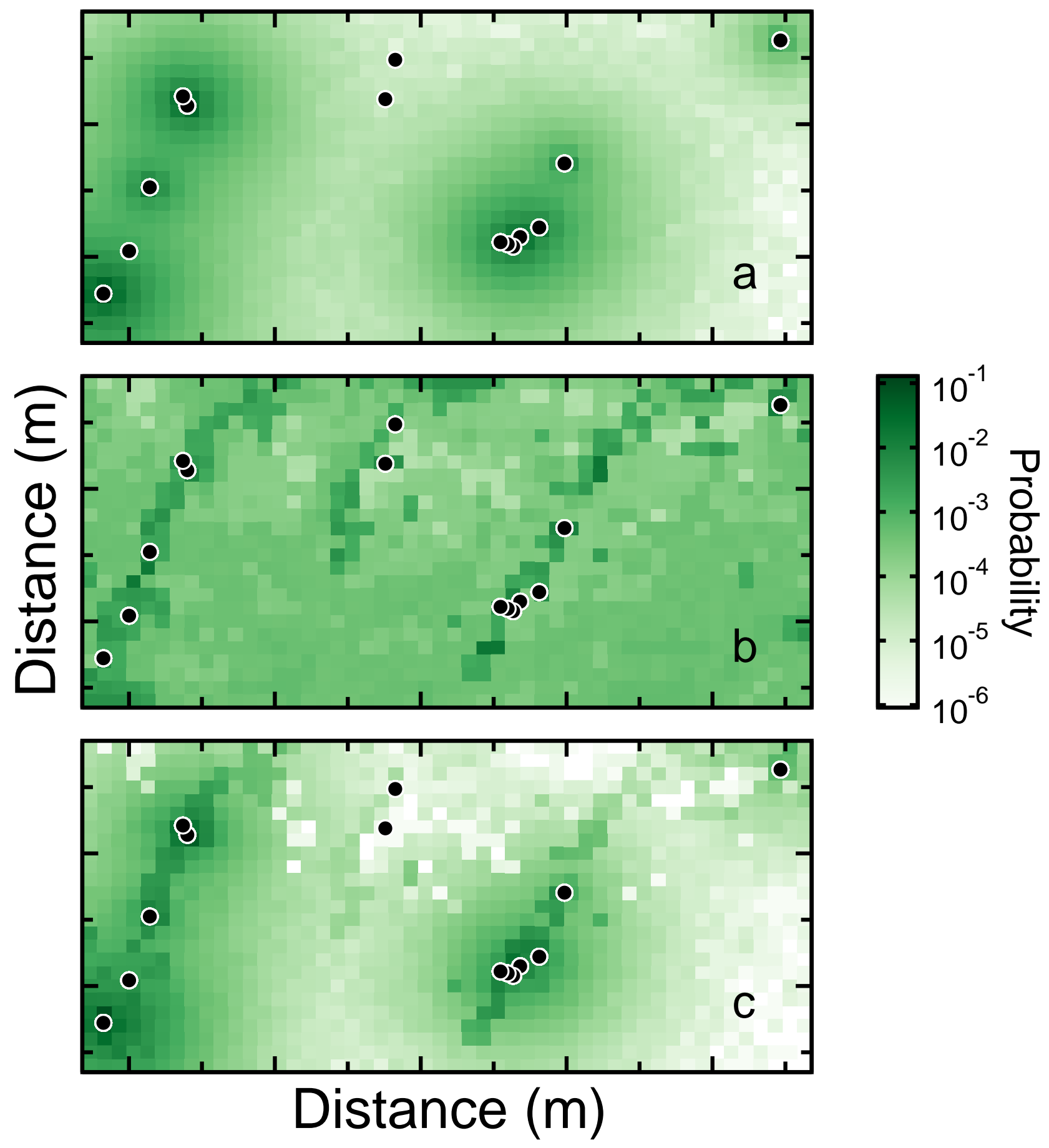


Figure 3
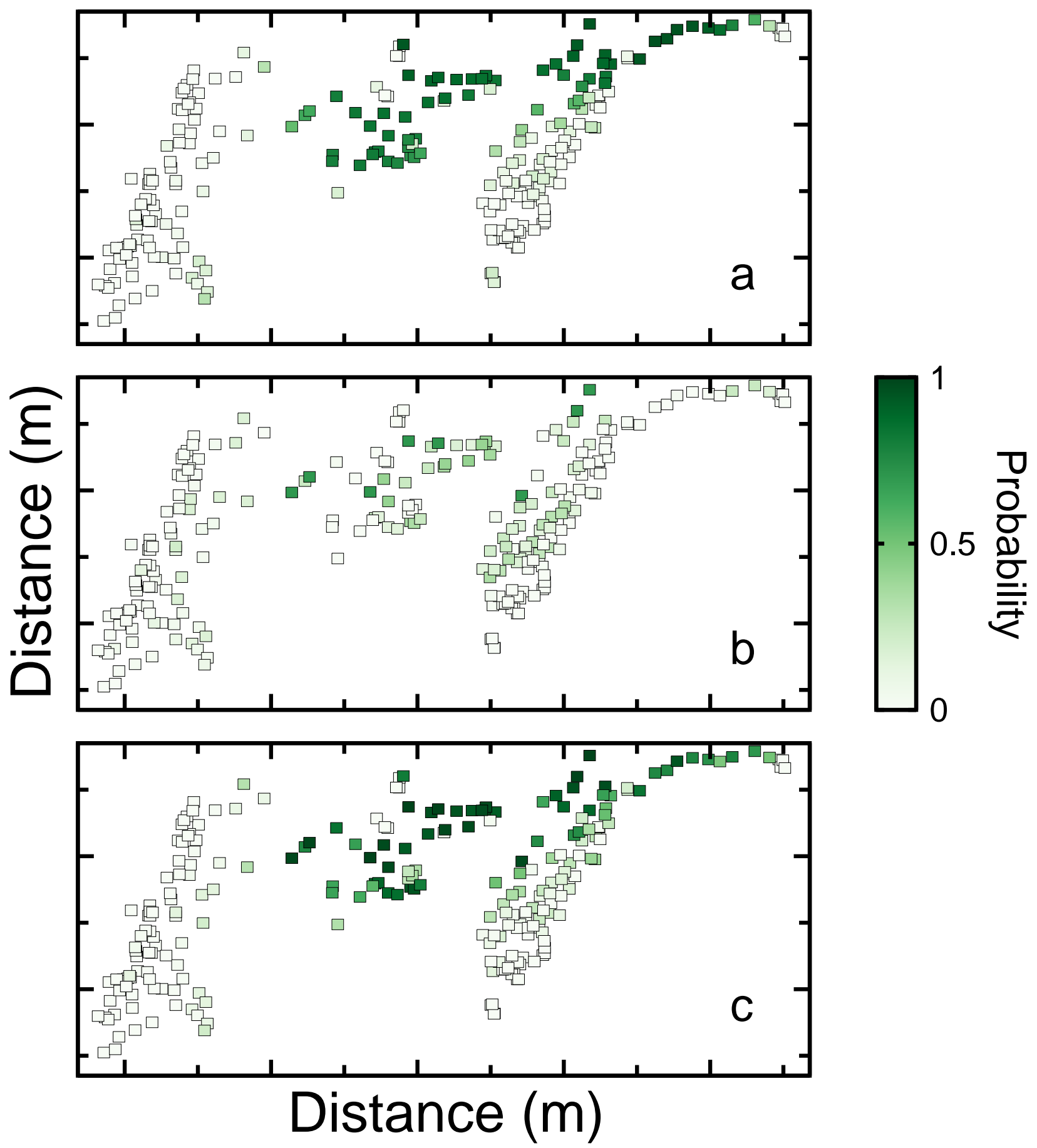
Figure 4

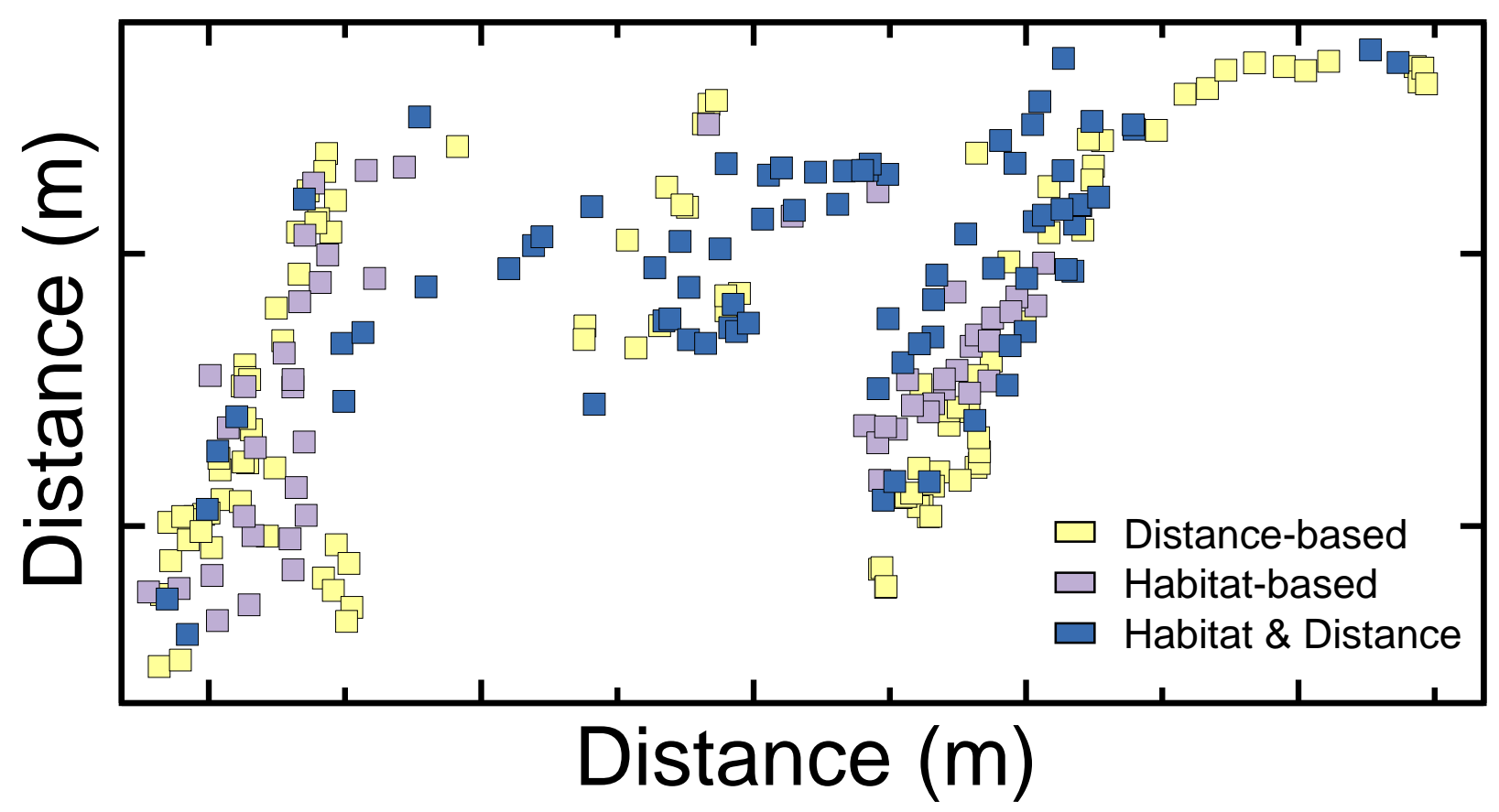

